\title{
Experimental Validation of Computer Simulation of Deformations in Hydraulic Hoses
}

\author{
Jorge Rodriguez, PhD. ${ }^{1}$, and Mitchel Keil, PhD. ${ }^{1}$ \\ ${ }^{1}$ Western Michigan University, USA, jorge.rodriguez@wmich.edu
}

\begin{abstract}
Nowadays in academics and industry, where multiple computer-based tools are being employed for design and analysis of engineering systems, it is of chief importance to provide to the user of such software tools information about the importance of validation in a lab-setting. It can be said that it is even more important in academics because students are at the initial phase of their engineering formation. Towards that end, a project involving flexible elements, such as hoses and cables, was utilized to get students involved in a validation exercise. Flexible elements are absolutely essential to the safe and successful operation of any vehicle, but they are often difficult to design and define because they are subject to large elastic deformations and because of their potential collisions with other components. This combination of factors leaves flexible elements to be rushed into production near the end of a design cycle. Therefore, in collaboration between industry and academia, a CAE-based scheme has been developed and has been implemented as a software tool to assist in the design (routing) of flexible components. For validation purposes, a group of four students in a Capstone Design Course were asked to apply Reverse Engineering (RE) techniques to measure points along an actual hose and enter those points into the simulation software for comparison and validation of the model. This validation process is the work presented in this manuscript.
\end{abstract}

Keywords-Hoses, validation, deformations.

Digital Object Identifier (DOI): http://dx.doi.org/10.18687/LACCEI2015.1.1.252

ISBN: 13 978-0-9822896-8-6

ISSN: $2414-6668$

$1^{\text {th }}$ LACCEI Annual International Conference: "Engineering Education Facing the Grand Challenges, What Are We Doing?" July 29-31, 2015, Santo Domingo, Dominican Republic

ISBN: 13 978-0-9822896-8-6

ISSN: $2414-6668$

DOI: http://dx.doi.org/10.18687/LACCEI2015.1.1.252 


\title{
Experimental Validation of Computer Simulation of Deformations in Hydraulic Hoses
}

\author{
Jorge Rodriguez, $\mathrm{PhD}$, MBA, Mitchel Keil, $\mathrm{PhD}$ \\ Western Michigan University, USA \\ jorge.rodriguez@wmich.edu
}

\begin{abstract}
Nowadays in academics and industry, where multiple computer-based tools are being employed for design and analysis of engineering systems, it is of chief importance to provide to the user of such software tools information about the importance of validation in a lab-setting. It can be said that it is even more important in academics because students are at the initial phase of their engineering formation. Towards that end, a project involving flexible elements, such as hoses and cables, was utilized to get students involved in a validation exercise.
\end{abstract}

Flexible elements are absolutely essential to the safe and successful operation of any vehicle, but they are often difficult to design and define because they are subject to large elastic deformations and because of their potential collisions with other components. This combination of factors leaves flexible elements to be rushed into production near the end of a design cycle. Therefore, in collaboration between industry and academia, a CAE-based scheme has been developed and has been implemented as a software tool to assist in the design (routing) of flexible components. For validation purposes, a group of four students in a Capstone Design Course were asked to apply Reverse Engineering (RE) techniques to measure points along an actual hose and enter those points into the simulation software for comparison and validation of the model. This validation process is the work presented in this manuscript.

\section{Keywords—Hoses, validation, deformations.}

\section{INTRODUCTION}

As critical as hoses and cables are for the safe operation of any vehicle, they are among the less glamorous components in vehicular design. They are often difficult to design because they are subject to large elastic deformations and potential collisions with other components ${ }^{6}$. This combination of factors leaves cables and hoses to be rushed into production near the end of a design. These components present another problem related to this delay: they rarely are incorporated into the vehicles' solid model.

A collaboration between industry and academia was formed to address this problem. The objective was to develop a CADbased scheme, and it was implemented as a software tool to assist in the design (routing) of flexible components. As a requirement for this software tool, it should be capable to predict the position and motion of system's components as connection and mounting points are moved and accelerated in accordance with expected operation of the system. Additionally, proper interface and interaction with CAD software packages currently being utilized in the automotive industry is required.

The implemented tool has been tested with brake hoses. The use of three-dimensional cubic splines in combination with discrete flexible links has resulted in an adequate solid representation of the flexible elements. As with all softwarebased engineering tools, it is required to have validation of the implementation. In order to do so with the proposed CADbased tool it was necessary to apply Reverse Engineering (RE) techniques. Towards this end, as a Capstone Design Project in our Engineering Design Technology program, a testing fixture to have wheel/suspension components was built and a digitizing arm was utilized for the accurate collection of key points before and after operation scenarios. A group of four students received the experience of working on an industry-sponsored project, where design, implementation, redesign and adjustment phases were included. The results from this project demonstrate the importance of validation of implemented software-based tools in order to consider them useful ones.

\section{METHODOLOGY}

This project is a collaboration between our College of Engineering and Applied Sciences (CEAS) and industry. The main objective of the collaboration was the development of a CAD-based tool for the routing of flexible components, specifically the brake hoses. As one of the important steps in such development and implementation, a validation phase needed to be carried out. Given the scope of the specific task, and the global objective for the project, it was decided that this would make a wonderful senior design project. When this project was presented to the senior group, it resulted very attractive to them because they would be working on an industry-sponsored project, because it had design and implementation phases, and because they would be exposed to new technologies. The group was given the task to RE the location of brake hoses on a PT Cruiser. This car was a production unit not certified for street driving. In order to do the RE, students had access to a digitizing Faro Arm. These factors were very exciting for the students, but at the same time there were some challenges and problems for the team.

Design Space. The first one of those problems came up because the wheels made it practically impossible to take any 


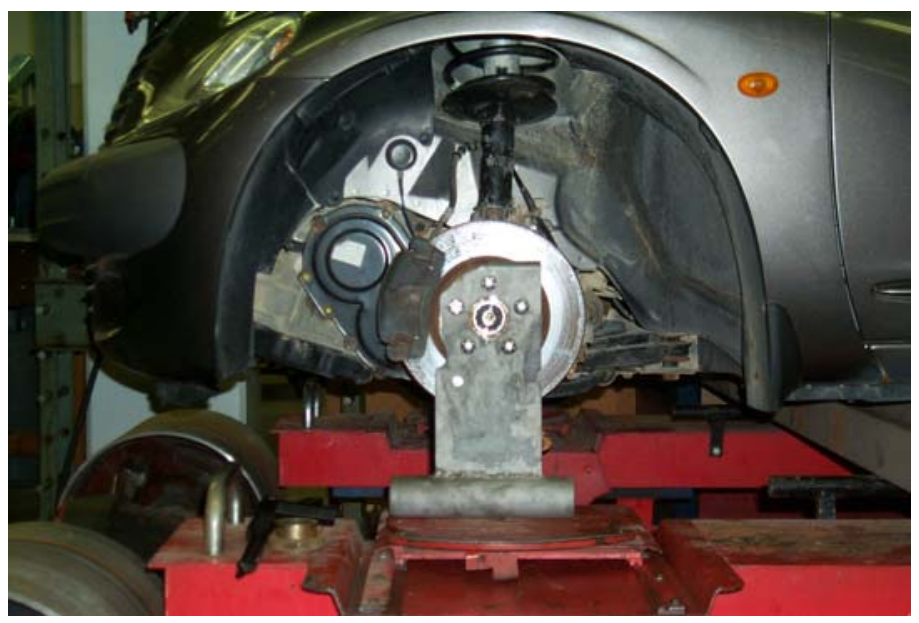

Figure 1. Steel foot in place of wheel to facilitate measurement.

measurements with them in place. The students responded by creating a steel foot to replace the front wheels. Figure 1 shows the left steel foot in place. It is important to note that even with the wheel in place, the use of RE was providing more 'realistic' information than what the CAD models have provided.

Reference Frame. The next issue to address was reference points, another learning experience for the team. In order to make measurements consistent and repeatable, three bolt heads from a metallic cover in the car were center drilled and used to set up a frame of reference as indicated in Figure 2. It was expected, once again, that the CAD models would provide accurate information about the location of these three bolt heads, but slight adjustments were required in order to accurately represent their location. The selection of these three points was on the basis that they would serve as a quick check of how good the measurement data was.

Data Collection. All measurements were performed with a Silver Edition Faro Arm pictured in Figure 3. An accurate comparison between the actual hose measurements and the numerical results given by the simulation software was accomplished by setting up reference markers ${ }^{3}$ in the simulation. The markers (i.e., points of interest) were established at the connection points of the hose to the vehicle frame and at several locations along the length of the hose. This was initially done for straight hose as shown in Figure 4. Small mass-less spheres ${ }^{4}$ were placed at the markers in the model for good visibility during motion simulation runs.

Once the hose was deflected into position, the measured location of these points was placed in the model and attached to the ground. The distance between the marker on the hose and ground was a measurement needed for comparison.

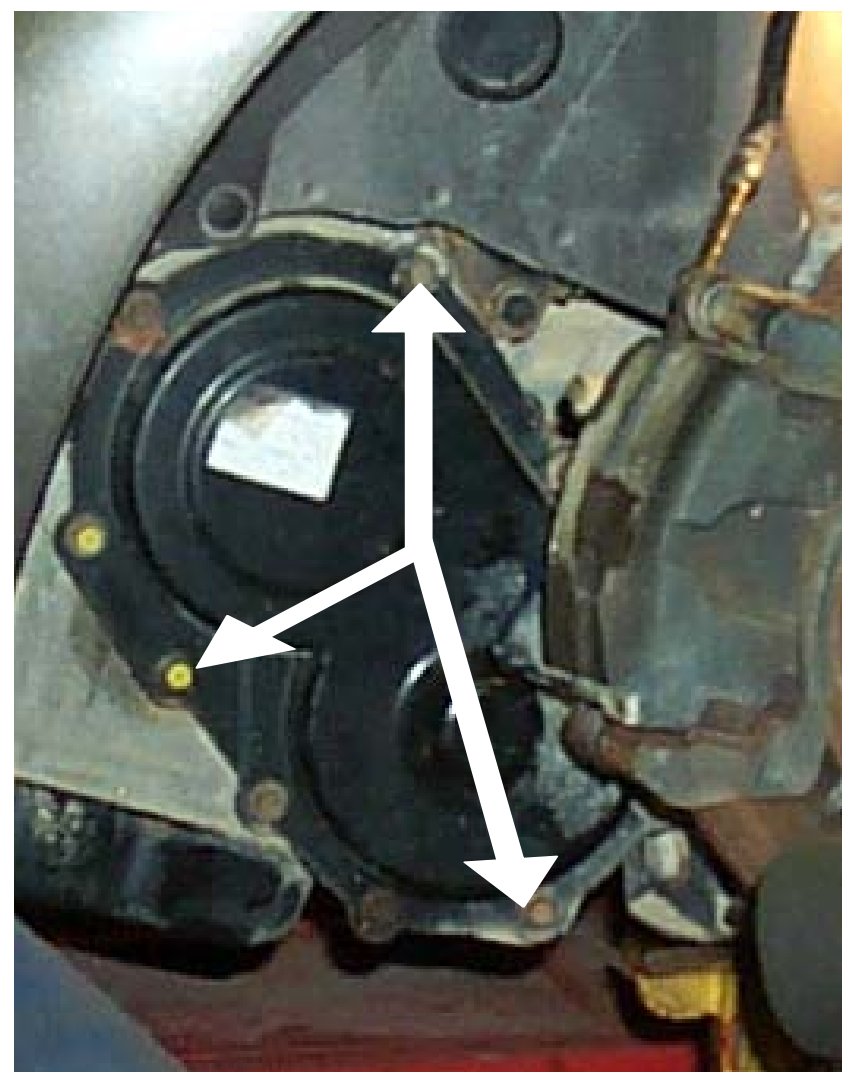

Figure 2. Bolt heads used to set up reference frame.

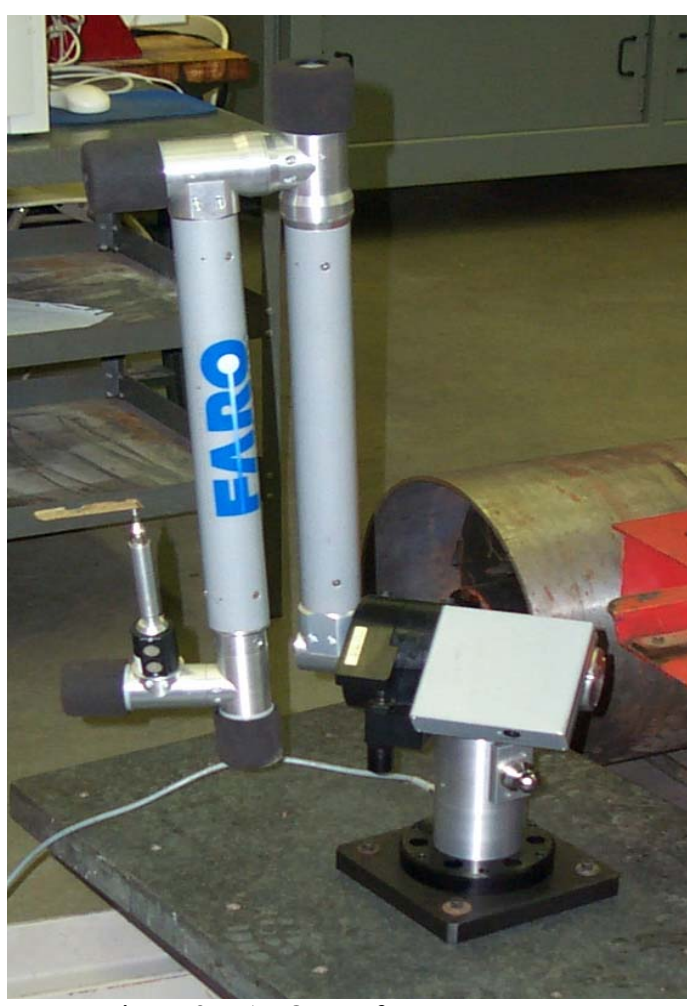

Figure 3. FARO arm for measurement. 


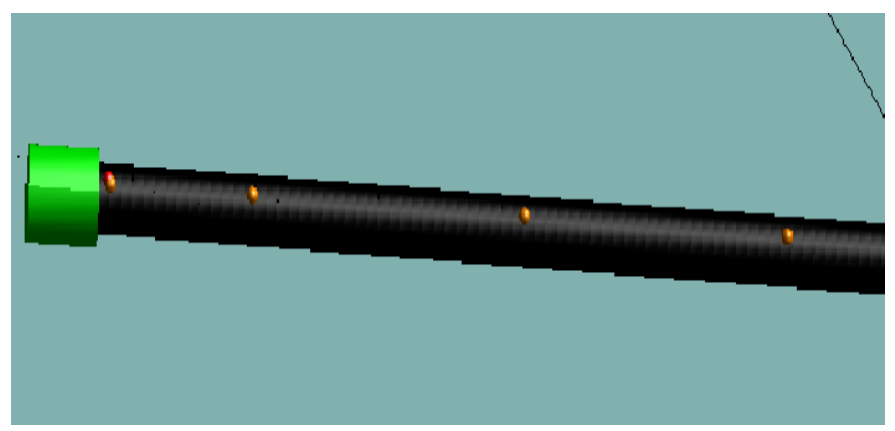

Figure 4. Mass-less spheres placed at markers on the hose.

Placement on CAD. A CAD model of some of the vehicle's geometry had been supplied by our industry partner, and it was initially thought that this model could be used to establish connection points and to provide a quick check of proper hose location. It was soon discovered that several configurations had evolved between model and vehicle ${ }^{2}$, thus coming to face the real-life situation where documentation does not correspond to actual system, another learning experience for the students. An illustration of this problem can be seen in Figure 5. Here the golden spheres represent points on crimp connectors, and green spheres represent points on the hose. It can be observed the crimp connectors are in completely different locations, thus resulting in wrong location for hose markers as well. Therefore, the team needed to work on the location of the crimp connectors had to be reengineered into the model from measurements taken on the vehicle.

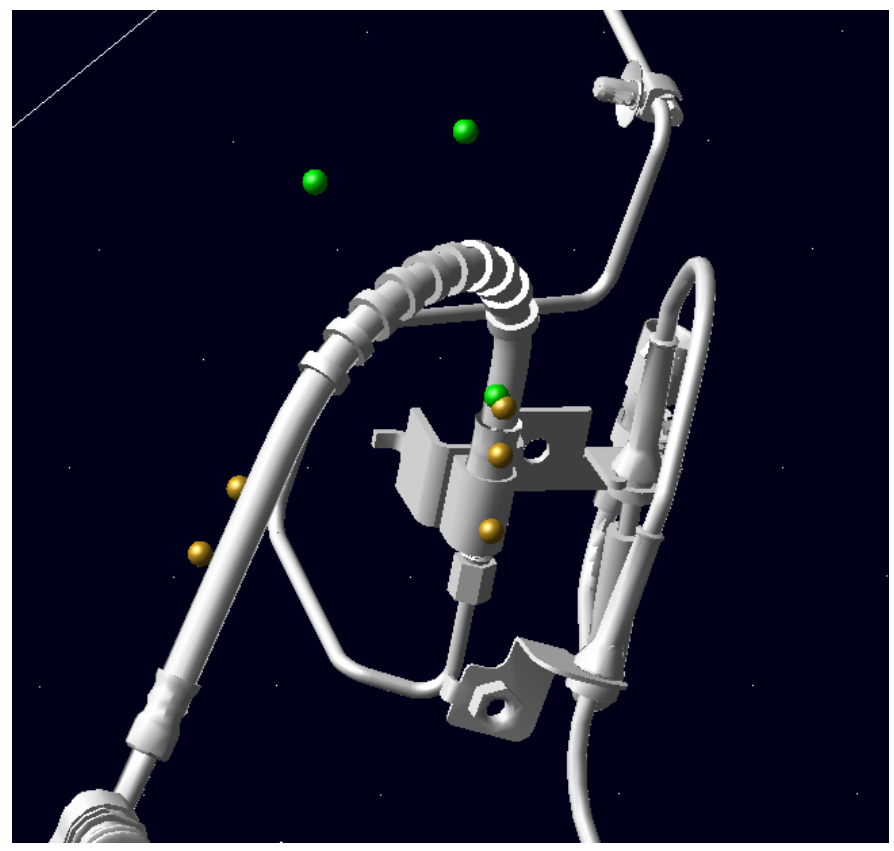

Figure 5. Measured points positioned relative to CAD model.

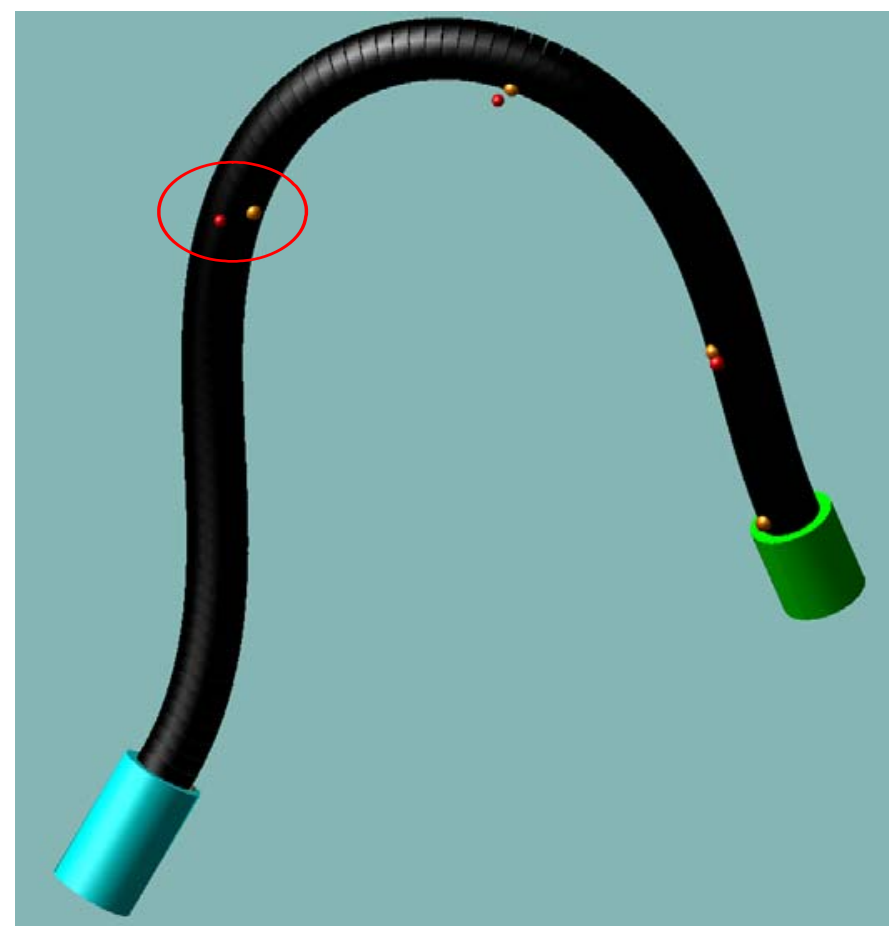

Figure 6. The positioned hose model.

Comparison. Once the physical locations were collected and properly indicated in the CAD model, the simulation is run, and digitized points and marker points are compared for relative locations.

\section{RESULTS}

The validation results are as follows. Figure 6 shows the results for marker points of the hose model being placed into proper position. In this configuration, only the crimp connection points have been matched up. The locations of markers on the hose were determined from the model.

Measured points are shown in red. The points with maximum deviation between model and measurement have been circled. The distance between these two points was also measured as the hose was positioned. As can be seen from the figure, the maximum deviation was found to be $5.5 \mathrm{~mm}$ or 0.21 inches, which was considered adequate based on the methodology and level of accuracy carried out during the procedure.

The students made several attempts to transfer the model directly into CAD software ${ }^{1,5}$ using IGES, STEP, and Parasolid formats.Version mismatches, other incompatibilities, and, ultimately, time prevented this from happening. 


\section{CONCLUSIONS}

This project has been a wonderful experience for the students in the Capstone Design course. They have worked on real-life situation, where many issues and challenges needed to be addressed as the project was going on. And even better for them, according to their comments, they learned a lot about how to use textbook material in industry and they had the opportunity to interact with engineering practitioners in order to satisfy the technical requirements of the project.

Regarding the technical aspect, this needed validation study has brought to light several potential sources for error. Error from measurement is always possible especially given the nature of rubber hose and other flexible components. Extreme care must be taken in order to keep from displacing the hose during measurement. The need to reengineer the mount points into the model only exacerbates the measurement problem. Flexible component properties could also contribute to the error. However, the model shows promise; and the ability to extract results from the simulation software, both quantitative and qualitative, is invaluable. Furthermore, the promise of taking these models directly into the CAD model, as is the global objective of the project, to give an early design presence is imminent.

\section{ACKNOWLEDGEMENTS}

The authors would like to acknowledge several people who contributed to this work. The student team of Louis Davis, Scott Fulcher, Jeremy Gehoski, Benjamin Koenig, and Martin Swiecki were instrumental in fabricating fixtures, collecting and entering data, and setting up the experiment. Staff and faculty members G. Hall. J. Vanderpolder, and F. Z. Sitkins offered timely advice and assistance at several stages of the work. Finally, the authors would like to acknowledge Mr. Marc Hemmye of Daimler Chrysler for providing funding, models, and the College of Engineering and Applied sciences to facilitate this study.

\section{REFERENCES}

1. Dessault Systemes. CATIA User's Manual. CATIA V5R4, 2000.

2. Hemmye, Marcus. Personal interview, March 22, 2001.

3. http://www.mdii.com/mdii

4. Janevic, John. Personal interview, February 16, 2001.

5. Toogood, Roger. Pro/Engineer Advanced Tutorial

6. Waurzyniak, Patrick (2001). Manufacturing Engineering, 124

(4). 